\title{
Further Electrochemical and Behavioural Evidence of a Direct Relation- ship Between Central 5-HT and Cytoskeleton in the Control of Mood
}

\author{
Francesco Crespi*
}

\author{
Biology Department, Neurosciences CEDD GlaxoSmithKline, Medicines Research Centre, via Fleming 4, 37135 \\ Verona, Italy
}

\begin{abstract}
Reduced activity of CNS serotonin is reported in unipolar depression and serotonin is the major target of recent antidepressant drugs. However, an acute depletion of serotonin in healthy individuals does not induce depressive symptoms suggesting that depression does not correlate with the serotonin system only. Neuronal plasticity (structural adaptation of neurons to functional requirements) includes synthesis of microtubular proteins such as tyrosinated isoform of $\alpha$ tubulin and presence of serotonin as regulator of synaptogenesis. In depression neuronal plasticity is modified.

Here, in rats submitted to a behavioural test widely used to predict the efficacy of antidepressant drugs (forced swimming test: FST) a significant decrease of both cerebral tyrosinated $\alpha$-tubulin expression and serotonin levels is monitored. Moreover, treatment with para-chlorophenylalanine (PCPA, compound that specifically depletes brain serotonin) but not alpha-methyl para tyrosine ( $\alpha$-MPT, compound that blocks synthesis of catechols: chemicals also implicated in depression) significantly reduced tyrosinated $\alpha$-tubulin. Thus, a direct relationship between serotonin and tyrosinated $\alpha$-tubulin appears to be present both in "physiological" and in "pathological" states. In addition, data obtained in animals submitted to FST and/or treated with the selective serotonin reuptake inhibitor (SSRI) fluoxetine further support the interrelationship between central serotonin and cytoskeleton. These data propose that direct relationship between serotonin and tyrosinated $\alpha$-tubulin could be considered within the mechanism(s) involved in the pathogenesis of depression.
\end{abstract}

Keywords: Rat brain, monoamines, serotonin, microtubules, tyrosinated $\alpha$-tubulin.

\section{INTRODUCTION}

The cytoskeleton is the structural component of neurones and three polymers, i.e. microtubules, intermediate filaments and microfilaments are their components [1].

Microtubules derive from the polymerisation of tubulin proteins (heterodimers consisting of $\alpha$ - and $\beta$ - sub-units), they are abundant in neurones and exhibit high heterogeneity of components. Furthermore, microtubules are highly dynamic polymers as they exchange rapidly the polymerised tubulin dimers with soluble sub-unit pools. This feature is involved in fundamental cellular functions such as cell division, motility and transport, maintenance of cell shape and signal transduction [2].

The $\alpha$-tubulin sub-unit of the microtubule is expressed in mammalian species in various isoforms related to different primary sequences and several post-translational modifications. One of these modifications is the cyclic tyrosination / detyrosination of the C-terminus, cycle that has been shown to occur in many cell types and to be related to the microtubule dynamic [3]. Stable microtubules are detyrosinated [4], whilst the highly dynamic microtubules show to be highly tyrosinated [3].

High levels of tyrosinated $\alpha$-tubulin (Tyr-tub) are currently used as a marker of dynamic forms of microtubules [3,

\footnotetext{
*Address correspondence to this author at the Biology Department, Neurosciences CEDD GlaxoSmithKline, Medicines Research Centre, via Fleming 4, 37135 Verona, Italy; Tel +390458218707;

E-mail: Francesco.M.Crespi@GSK.com
}

$5,6]$. Its expression is increased in physiological events such as the development of the central nervous system $[7,8]$ as well as pathological events such as experimental epileptogenesis, characterised by neuronal plasticity [9].

Neuronal plasticity is the capability of neurones to modify their structural organisation in order to adapt to new functional requirements. It plays a crucial role within brain development and in many physiological processes of mature brain such as learning and memory [10]. Neuronal plasticity requires the presence of serotonin $(5-\mathrm{HT})$ as regulator of synaptogenesis [11] and cytoskeletal states necessary for synaptic remodelling i.e. dynamic form of microtubules [12]. Indeed, a more dynamic microtubule (major presence of soluble form versus insoluble form) is essential for rapid intracellular events resulting in elongation or shortening of cell processes, which are essential morphogenetic events during neurogenesis [1].

Recently, basic and clinical studies have provided direct evidence of neuronal plasticity failure in response to stress and depression that leads to neuronal atrophy, cell death and neurogenesis decrease in the hippocampus [13-16].

Several neurotransmitters have been implicated in the pathogenesis of depression. Reduced activity of monoamines such as 5-HT and noradrenaline (NA) systems has been reported in sub-groups of patients with major depression [17] and antidepressant drugs act mostly via increased amount of such neurotransmitters in the synaptic space.

To date the 5-HT system is one of the major targets of antidepressant drugs and Selective Serotonin Reuptake In- 
hibitors (SSRIs) are highly effective, producing milder side effects than tricyclic antidepressant drugs [17-21].

However, depletion of 5-HT or NA in healthy subjects does not induce clinically significant depressive symptomatology. Thus, abnormalities in other neurobiological systems may play a role in depressive symptomatology [17]. For instance, various studies have proposed that the increased central 5-HT levels following a long-term antidepressant treatment activate several post-receptor signalling pathway and in particular that of Protein Kinase A (PKA) in microtubules, resulting in the inhibition of microtubule assembly [12, 2224].

The consequent major dynamic instability of the microtubules may favour the cytoskeletal changes necessary for long-term (plastic) modifications in neurotransmission [25]. Taken together with the neuronal plasticity failure observed in stress and depression, these findings support the cytoskeleton as one of the systems involved in depression.

In the present study, that follows preliminary work presented to the 15th ECNP Congress [26], experiments have been performed in order to monitor a putative interrelationship between cytoskeleton and cerebral monoamines. In particular, the influence of pharmacological depletion of catechols or serotonin (5-HT) upon Tyr-tub levels has been analysed. Naive rats were treated either with $\alpha$-methyl-paratyrosine $(\alpha \mathrm{MPT})$ that blocks synthesis of catechols [27, 28] or with para-chlorophenylalanine (PCPA) a tryptophan hydroxylase inhibitor that conspicuously decreases central 5HT content without altering 5-HT terminal density [29, 30].

Finally the FST: an animal model widely used to predict the efficacy of antidepressant drugs as it is stated by the first author proposing such behavioural model [31] and then adopted by the researchers of the field, was applied either alone or in presence of treatment with fluoxetine. Therefore this model considered as "predictor" of the efficacy of antidepressant drugs such as the SSRIs was used in order to analyse the two systems studied i.e. 5-HT and cytoskeleton, within either a condition that could mimic a "depressive state" and following treatment with an "antidepressant drug".

\section{METHODS}

\subsection{Animals}

Adult male Sprague Dawley rats (250-300g) were used. All housing and experimental procedures were carried out in accordance with the Italian law (Legislative Decree no.116, 27 January 1992), which acknowledges the European Directive 86/609/EEC, and were fully compliant with GlaxoSmithKline policy on the care and use of laboratory animal and codes of practice. Furthermore, all efforts were made to minimize the number of animals used and their suffering.

\subsection{Treatments} with:

Adult male Sprague Dawley rats (250-300g) were treated
1) PCPA $(500 \mathrm{mg} / \mathrm{kg}$ i.p. $\mathrm{n}=4)$ or
2) with $\alpha$ MPT $(250 \mathrm{mg} / \mathrm{kg}$ i.p. $\mathrm{n}=4)$ or
3) vehicle $(\mathrm{NaCl} 0.9 \% 2 \mathrm{ml} / \mathrm{kg}$ i.p., $\mathrm{n}=4$, control group).

24 hours later rats were anesthetised with chloral hydrate $(400 \mathrm{mg} / \mathrm{kg}$ i.p.), then were sacrificed, the brains were removed and homogenised in lysis buffer.

Subsequently, concomitant electrochemical analysis of both DA and 5-HT levels (using differential pulse voltammetry, see below) and Tyr-tub expression (western blot) were performed in each brain homogenate.

4) In other animals, acute treatment with fluoxetine (SSRI $20 \mathrm{mg} / \mathrm{kg}$ i.p., $\mathrm{n}=4$ ) or vehicle $(\mathrm{NaCl} 0.9 \%$ $2 \mathrm{ml} / \mathrm{kg}$ i.p., $\mathrm{n}=4$, control group) was performed. Two hours later rats were anesthetised with chloral hydrate ( $400 \mathrm{mg} / \mathrm{kg}$ i.p.), then were sacrificed, the brains were removed and homogenised in lysis buffer.

Subsequent analysis of both 5-HT levels (voltammetry, see below) and Tyr-tub expression (western blot) were performed.

\subsection{Western Blot Procedure}

Tyr-Tub expression was evaluated in brain homogenate by densitometric quantification of related band previously obtained via western blot.

In particular, brains were homogenised in lysis buffer [5mM Tris- $\mathrm{HCl}$, 2mM EGTA, 0.1mM phenylmethylsulfonyl fluoride (PMSF), 0.1mM pepstatin A, $1 \mathrm{mM}$ leupeptin, $1 \mathrm{mM}$ aprotinin, $\mathrm{pH}$ 8.0]. Protein concentrations were determined via colorimetric assay (Bradford protein assay; Bio-Rad Hercules, CA, USA), setting the spectrophotometer to 595

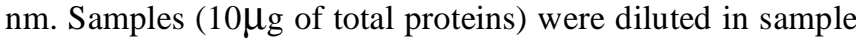
buffer [62.5mM Tris- $\mathrm{HCl} \mathrm{pH}$ 6.8, 20\% glycerol, $2 \%$ sodium dodecyl sulfate (SDS), $5 \% \beta$-mercaptoethanol, $0.5 \%$ bromophenol blue (BPB)]. Protein samples were heated for $3 \mathrm{~min}$ at $99^{\circ} \mathrm{C}$ and proteins were separated on SDS - $12 \%$ polyacrylamide gel electrophoresis, at $40 \mathrm{~mA}$ for $1 \mathrm{hr}$ and then transferred onto nitrocellulose membranes using a dry transfer unit at 50mA overnight. A molecular size marker (200$6.5 \mathrm{kD}$ range; Bio-Rad) and pure tubulin (ICN Costa Mesa, CA, USA) were used in order to exactly locate tubulin $(55 \mathrm{kD})$ on the basis of its position on the gel. The membranes were blocked for 2 hours with $5 \%$ skimmed powder milk in Tris-buffered saline (TBS) and incubated $1 \mathrm{hr}$ at $4{ }^{\circ} \mathrm{C}$ with monoclonal antibodies clone TUB-1A2 (Sigma) specific to Tyr-Tub at 1:1000 dilution in $0.1 \%$ skimmed powder milk in TBS. The membranes were then incubated with a 1:5000 IgG anti-mouse alkaline phosphatase antibody (Promega Madison, WI, USA) for $30 \mathrm{~min}$ and the reaction developed using a stabilized substrate for alkaline phosphatase (Western Blue; Promega). The immunoreactivity of the Tyr-Tub bands obtained was quantified by densitometry (Molecular Analyst Software; Bio-Rad).

\subsection{Voltammetry and Carbon Fibre Micro Electrodes (Micro-Biosensors)}

Within the different voltammetric methodologies available, Differential Pulse Voltammetry (DPV, that is a linear voltammetric technique with superimposed constant pulses $(\triangle \mathrm{V}: 50 \mathrm{mV} ; \mathrm{t}: 50 \mathrm{~ms})$ has been selected since this technique exhibits both a high selectivity and sensitivity (for a review see Stamford et al. [32]). DPV was applied by means of the polarograph $\mu$ AUTOLAB (EcoChemie, The Netherlands) 
linked to IBM computer with voltammetric analysis program (General Purpose Electrochemical System Software package (GPES). The three-electrode potentiostat system needed to apply voltammetry was prepared as described previously $[32,33]$. Briefly, the reference electrode was silver/silver chloride $(\mathrm{Ag} / \mathrm{AgCl})$ and the auxiliary (counter) electrode was a silver wire, both approximately $100 \mu \mathrm{m}$ diameter. The working electrode was the $30 \mu \mathrm{m}$ diameter mCFE prepared and treated as previously described in order to increase the sensitivity, selectivity and reliability of the micro-sensor (34). Briefly, a $70 \mathrm{~Hz}$ triangular wave form was applied in three stages, 0 to +3 Volts for $8 \mathrm{sec}$; 0 to $+2.6 \mathrm{~V}$ and 0 to $+1.5 \mathrm{~V}$ for $10 \mathrm{~s}$ each. Then, two successive continuous potentials were applied to the mCFE: $+1.45 \mathrm{~V}$ and $-0.9 \mathrm{~V}, 5 \mathrm{~s}$ each. This electrochemical treatment was carried out with the auxiliary, reference and working electrodes immersed in $0.1 \mathrm{M}$ phosphate-buffered saline (PBS) at $\mathrm{pH}$ 7.4. It affects the active part of the working electrode i.e. the tip of the protruding carbon fibre from the end of the glass pipette (0.5-1.0 $\mathrm{mm}$ length; $30 \mu \mathrm{m}$ diameter). Then the tip was coated with Nafion as described in details by Crespi et al. [34]. Briefly: the tip of the mCFE was immersed four times (approximately 2 sec each time) into a Nafion drop ( $10 \mu 1$ of $5 \%$ solution, Solution Technology, Mendehall, PA) placed into a loop (about $3 \mathrm{~mm}$ diameter) formed at one end of a platinum wire of $100 \mu \mathrm{m}$ in diameter. The other end of the wire was connected to the reference and auxiliary outputs of the polarograph and a d.c. potential of $+3.5 \mathrm{~V}$ was applied. The Nafion-coated mCFE was then dried at $60^{\circ} \mathrm{C}$ for $20 \mathrm{sec}$ and used immediately for the experiments. This electrochemical treatment was shown to increase sensitivity, selectivity and reliability of the micro-sensor to quantification of dopamine and noradrenaline [catecholamines, both having similar oxidation potential value] and serotonin [34-36].

The following measuring DPV parameters were chosen: initial potential (Ei) $-100 \mathrm{mV}$, final potential (Ef) $+350 \mathrm{mV}$ to monitor catecholamines and 5-HT in the same scan voltammogram. Scan step was $10 \mathrm{mV} \cdot \mathrm{s}^{-1}$ scan duration, $30 \mathrm{~s}$, filter $0.1 \mathrm{~Hz}$. Other polarographic parameters employed were chosen according to Crespi et al. [34].

\subsection{Forced Swimming Test}

Other groups of naive rats were submitted to FST as described by Porsolt et al. [31], except that the water was deeper [37]. Briefly, each animal was placed in a cylinder $(40 \mathrm{~cm}$ height; $18 \mathrm{~cm}$ diameter) containing $30 \mathrm{~cm}$ water maintained at $26-28^{\circ} \mathrm{C}$. The modification of FST $(30 \mathrm{~cm}$ water deep) avoids false immobility due to the capability of adult rats to rest on the tail when touching the bottom of the cylinder in a lower volume i.e. $15 \mathrm{~cm}$ as described by Porsolt et al. [31].

In a recent paper, the influence of "cold" water upon rat behaviour and in particular immobility within FST was discussed [38]. In our hand rats submitted to FST with water at the temperature of $26-28^{\circ} \mathrm{C}$ were showing significant different behaviour immobility in function of different treatments (see Results and Discussion).

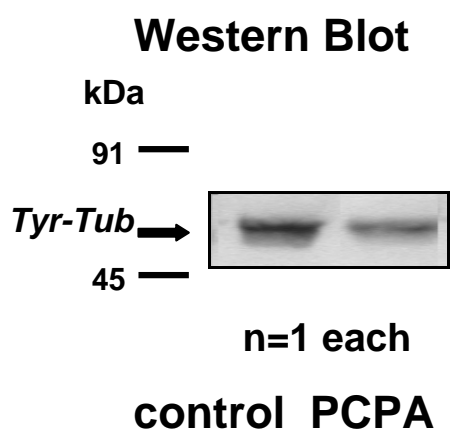

kDa

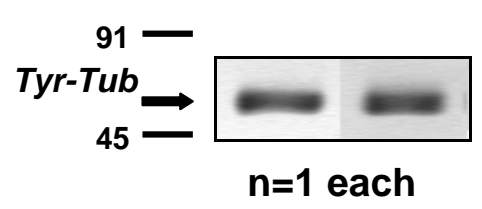

control $\alpha$ MPT

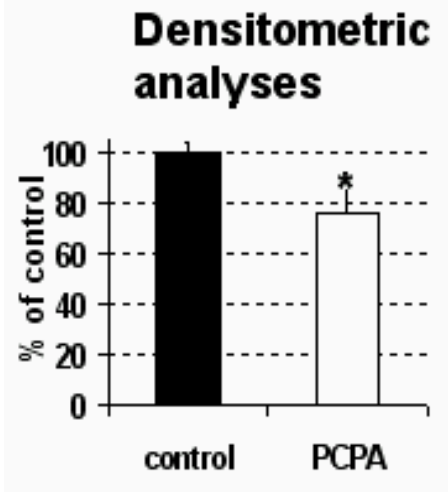

Densitometric analyses

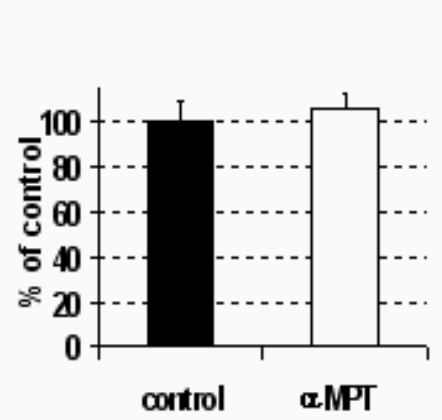

Voltammetric analyses

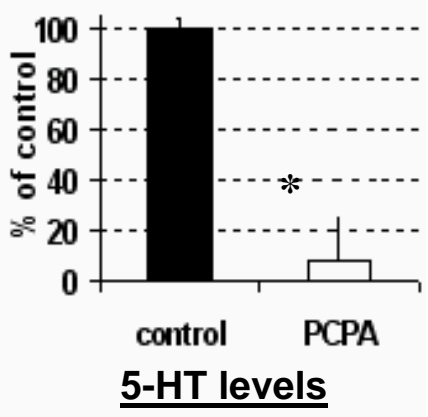

catechol levels

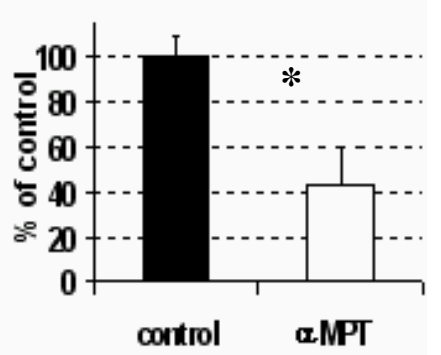

Fig. (1). Tyr-Tub (55kDa) immunoreactivity in brain homogenate: western blot bands (left) quantified by densitometric analysis and concomitant DPV measurements (right) after acute treatment with PCPA 500mg/kg i.p. (TOP) or with $\alpha \mathrm{MPT} 250 \mathrm{mg} / \mathrm{kg}$ (BOTTOM). Results are expressed as percent of control (vehicle treated rats); $\mathrm{n}=4$ each histogram, mean \pm S.D. $* \mathrm{p}<0.05$, Dunnett's test.

Note the significant decrease, $\left(F_{1,12}=7,5264 \mathrm{p}<0.05\right)$ of Tyr-Tub following PCPA versus $\alpha$ MPT treatment. 
After a pre-test session (day 1) of 15 min each rat was dried (under warm air current) and twenty-four hours later exposed again to FST during 5 min.

Both saline and fluoxetine sub-chronic treatment was performed $23 \mathrm{~h}, 5 \mathrm{~h}$ and $1 \mathrm{~h}$ prior to the FST as previously described [37, 39]. The behaviour was monitored during the first $5 \mathrm{~min}$ of the pre-test and the following day for all the five $5 \mathrm{~min}$ of the FST.
A time-sampling method was used as described previously [37] in order to score several behaviours during a single viewing. This method has been selected as it has shown to be reliable and valid for detecting the effect of different antidepressant drugs. In particular, immobility and swimming were monitored in 5-sec period. Briefly, immobility was scored when the animal was making the minimum movements necessary to keep its head above water and stay afloat. Swimming was scored when the animal actively
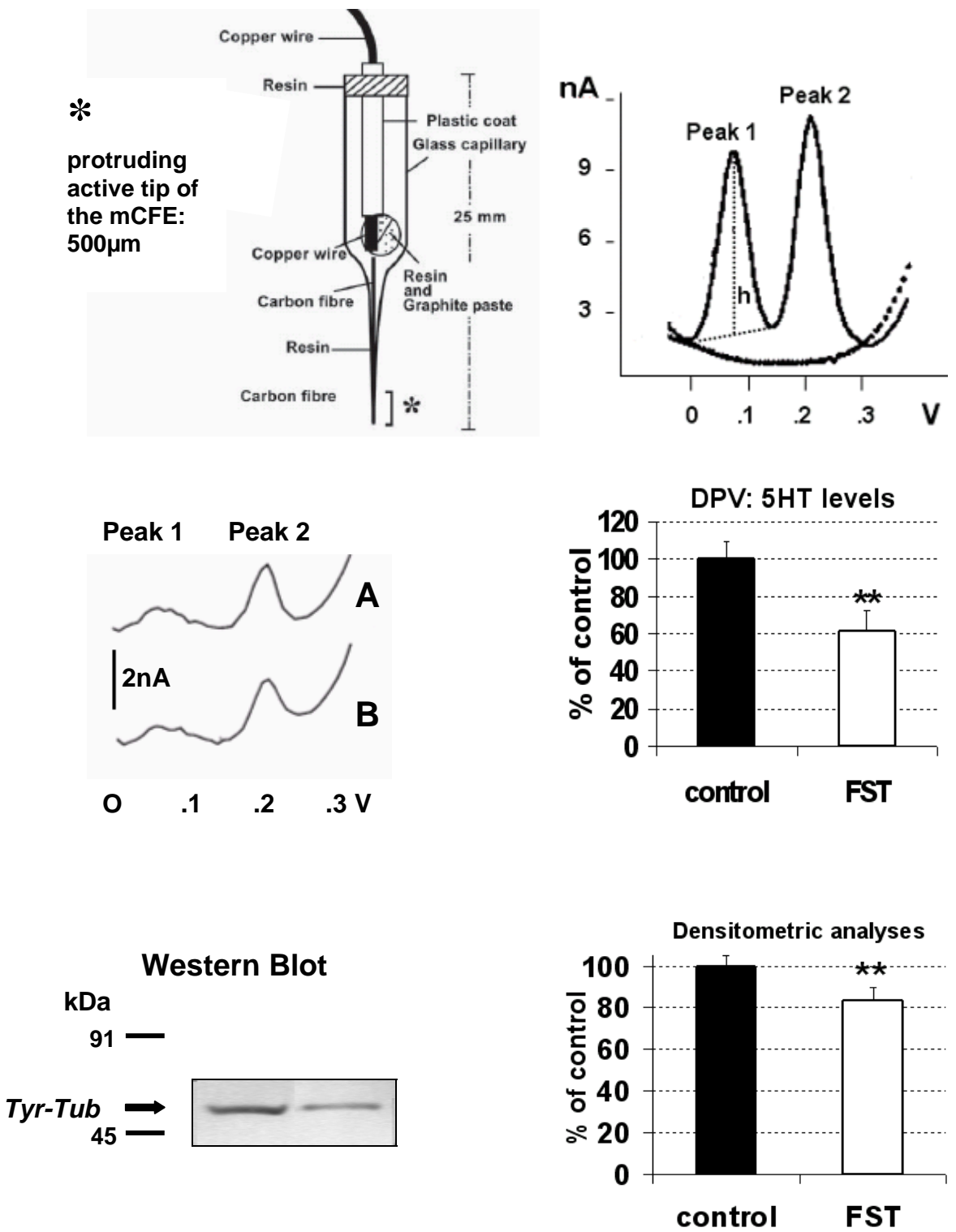

Fig. (2). TOP LEFT: schematic representation of the carbon fibre microelectrode used in the present experiments.

TOP RIGHT: differential pulse voltammogram obtained in vitro with Nafion mCFE: dotted line shows signals obtained in phosphate buffer solution (PBS, pH 7.4), solid line shows Peak 1 at approximately $69 \mathrm{mV}$ and Peak 2 at approximately $230 \mathrm{mV}$ corresponding to the oxidation of catecholamines [dopamine or noradrenaline] and 5-HT, respectively (50nM in PBS).

h: height of the peak, measured in nanoAmperes (nA: Intensity of current). This perpendicular line also determined the exact potential value expressed in Volts (V) of each signal on the abscissa.

MIDDLE: differential pulse voltammogram obtained in vitro with Nafion mCFE within $200 \mu l$ sample of the brain homogenate of a naïve (A) rat or a rat submitted to FST (B) (LEFT) and in six rats each group (RIGHT).

BOTTOM: In the same $200 \mu \mathrm{l}$ sample brain homogenate the Tyr-Tub (55 kDa) western blot immunoreactivity was performed (left) and quantified by densitometric analysis (right).

Results are expressed as percent of control (naive rats); $n=6$ each histogram, mean \pm S.D. ${ }^{* *} \mathrm{p}<0.01$, Dunnett's test. 
swam around the tank, making movements greater than that necessary to stay afloat.

Three groups of animals ( $\mathrm{n}=4$ each group) were submitted to FST: untreated rats (naive, $n=4$ ) or rats pre-treated with vehicle $(\mathrm{NaCl} 0.9 \%)$ or fluoxetine as described above.

Immediately after FST, each rat was sacrificed, the brain was removed and homogenised in lysis buffer so that ex vivo parallel experiments could be performed to monitor 5-HT levels and Tyr-Tub expression. Briefly, 5-HT levels were selectively measured within $200 \mu \mathrm{l}$ sample of brain homogenate using DPV associated with carbon fibre microelectrodes (mFE) coated with Nafion [34]. In the same brain homogenate assessed with DPV-mCFE the Tyr-Tub (55 $\mathrm{kDa}$ ) western blot immunoreactivity was performed and quantified by densitometric analysis.

\subsection{Drugs}

PCPA, $\alpha$ MPT, chloral hydrate, (Sigma St. Louis, MO, USA), fluoxetine (Tocris); Nafion (Aldrich).

\subsection{Statistical Analysis}

The data obtained from all the experiments were analyzed using analysis of variance (ANOVA) and the post-hoc test were conducted using Dunnett's test.

\section{RESULTS}

\subsection{Pharmacological Treatments}

i) PCPA treatment resulted in a significant decrease of Tyr-Tub expression in the whole brain (approximately $75 \%$ of vehicle treated rats $(\mathrm{NaCl} 0.9 \% 600 \mu 1$ i.p., control rats) (Fig. 1 TOP).

ii) In contrast, no significant changes were monitored in $\alpha \mathrm{MPT}$ treated rats (Fig. 1 BOTTOM).

Concomitant DPV measurements in the same homogenate resulted in a large decrease to approximately $45 \%$ or $12 \%$ of control values of both the catecholaminergic (Peak 1) and the 5-HT (Peak 2) related signals, respectively (Fig. 1 right, see also Fig. 2 for technicality).

iii) Acute fluoxetine $(20 \mathrm{mg} / \mathrm{kg}$ i.p. $)$ resulted in a significant increase of both 5-HT levels and Tyr-tub expression in whole brain up to approximately $217 \pm 40 \%$ and $203 \pm 24 \%$, respectively, of control rats treated with $\mathrm{NaCl} 0.9 \%$ (vehicle) $600 \mu$ li.p. (Fig. 3).

\subsection{Forced Swimming Test}

i) FST significantly increased immobility counts from $19.8 \pm 1.5$ (untreated rats) or from $16.8 \pm 1.0$ (vehicle treated rats) recorded in the pre-test day, up to $31.4 \pm 3.9$ or to $31.0 \pm 2.1$ gathered in day 1 , respectively (mean \pm SEM) (see Table 1).

In fluoxetine treated rats submitted to FST, immobility latency appeared to be increased (approximately $45 \mathrm{~s})$ while immobility counts were significantly decreased $(22.8 \pm 2.7$, mean \pm SEM) when compared to untreated rats $(31.4 \pm 3.9)$ or vehicle treated rats (31.0 \pm 2.1$)$. Furthermore, fluoxetine treated rats showed higher swimming behaviour and active behaviour counts when compared to untreated or vehi-

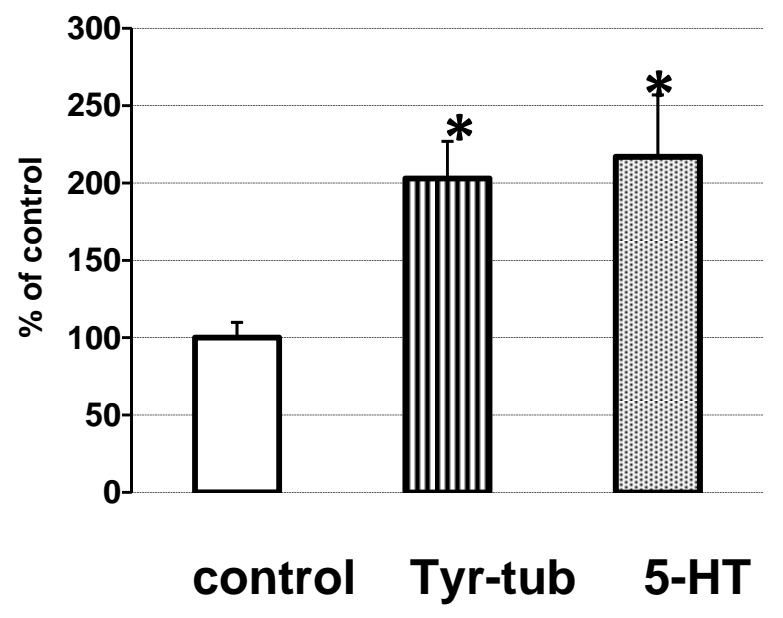

Fig. (3). Effect of acute treatment with fluoxetine alone $(20 \mathrm{mg} / \mathrm{kg}$ i.p. $\mathrm{n}=4)$ or vehicle alone $(\mathrm{NaCl} 0.9 \% 2 \mathrm{ml} / \mathrm{kg}$ i.p., $\mathrm{n}=4$, control group) upon voltammetric 5-HT levels or Tyr-tub expression in rat whole brain. Both parameters were significantly increased: $F_{1,8}=$ $8.202 \mathrm{p}<0.05)$ and $\mathrm{F}_{1,7}=7.727 \mathrm{p}<0.05$, respectively.

Data are expressed as $\%$ of control (vehicle), mean \pm S.D. ${ }^{*} \mathrm{p}<0.05$, Dunnett's test.

cle treated rats. In contrast, climbing behaviour counts were similar in all animals tested (Table $\mathbf{1}$ ).

ii) Immediately after FST, rats were sacrificed. The brains were immediately removed and homogenised. Successive concomitant electrochemical [voltammetric] and western blot analyses were performed in the whole brain homogenate of rats submitted to FST and showed that:

a) In vehicle treated rats 5-HT levels and Tyr-tub expression were both significantly decreased by FST to approximately $69 \pm 11 \%$ and $87 \pm 4 \%$ of corresponding levels monitored in naive control rats (Fig. 4). These data are in accord with the results gathered from the previous groups of animals submitted to FST and then tested for Tyr-tub expression and 5-HT levels as described in Fig. (2) middle and bottom.

b) In fluoxetine treated rats submitted to FST, 5-HT levels and Tyr-tub expression reached $120 \pm 16 \%$ and $103 \pm 5 \%$ of corresponding levels monitored in naive control rats, respectively. On the other hand, when compared to data gathered from vehicle treated rats submitted to FST and considered $100 \%$, these differences were approximately $150 \%$ and $116 \%$, respectively (Fig. 4).

c) in naive rats submitted to FST only, changes in 5-HT levels and Tyr-tub expression were very close to those monitored in vehicle + FST treated rats (Fig. 4).

\section{DISCUSSION}

Earlier in vitro studies have indicated that long-term antidepressant SSRI treatment inhibits microtubule assembly via PKA pathway activation [12]. This suggests that increased 5-HT levels (due to chronic SSRI treatment) precede the inhibition of microtubule assembly and therefore the increase of its dynamic instability. 
Table 1.

\begin{tabular}{|c|c|c|c|}
\hline \multirow{2}{*}{ BEHAVIOUR } & \multicolumn{2}{|c|}{ Untreated Rats } & \multirow{2}{*}{ ANOVA } \\
\hline & pre-test & FST & \\
\hline immobility latency (sec) & $114 \pm 18$ & $67 \pm 11$ & $\mathrm{~F}_{1,9}=5.07 \mathrm{p}=0.0543$ \\
\hline swimming (counts) & $21.8 \pm 2.5$ & $11.4 \pm 3.6^{*}$ & $\mathrm{~F}_{1,9}=5.38 \mathrm{p}=0.0489$ \\
\hline climbing (counts) & $16.6 \pm 3.3$ & $17.2 \pm 3.7$ & $\mathrm{~F}_{1,9}=0.01 \mathrm{p}=0.9082$ \\
\hline \multirow[t]{3}{*}{ active (counts) } & $40.2 \pm 1.5$ & $28.6 \pm 3.9^{*}$ & $\mathrm{~F}_{1,9}=7.47 \mathrm{p}=0.0257$ \\
\hline & \multicolumn{2}{|c|}{ Vehicle Rats } & \multirow[t]{2}{*}{ ANOVA } \\
\hline & pre-test & FST & \\
\hline immobility latency (sec) & $110 \pm 17$ & $65 \pm 8^{*}$ & $\mathrm{~F}_{1,9}=5.95 \mathrm{p}=0.0405$ \\
\hline diving (counts) & $2 \pm 1.2$ & 0 & $\mathrm{~F}_{1,9}=2.5 \mathrm{p}=0.1525$ \\
\hline \multirow[t]{3}{*}{ active (counts) } & $42.4 \pm 1.6$ & $29 \pm 2.1 * *$ & $\mathrm{~F}_{1,9}=24.39 \mathrm{p}=0.0011$ \\
\hline & \multicolumn{3}{|c|}{ FLUOXETINE Rats } \\
\hline & pre-test & FST & ANOVA \\
\hline immobility latency (sec) & $124 \pm 19$ & $112 \pm 19$ & $F_{1,9}=0,60 p=0.4579$ \\
\hline immobility (counts) & $17.6 \pm 1.9$ & $22.8 \pm 2.7$ & $\mathrm{~F}_{1,9}=2.90 \mathrm{p}=0.1266$ \\
\hline swimming (counts) & $19.2 \pm 5$ & $20.6 \pm 2.7$ & $\mathrm{~F}_{1,9}=0.06 \mathrm{p}=0.7987$ \\
\hline climbing (counts) & $22.6 \pm 3.2$ & $15 \pm 3.4$ & $\mathrm{~F}_{1,9}=2.45 \mathrm{p}=0.156$ \\
\hline
\end{tabular}

Our curiosity was then to analyse the possibility that these two systems could be interrelated and that changes in central serotonin could drive cytoskeleton modifications. This hypothesis, firstly indicated in a presentation to the 15 th ECNP Congress Barcelona - Spain, 5 - 9 October, 2002 [26] has been further tested via various analytical approaches:

\section{Treatment with PCPA or $\alpha-M P T$}

These are compounds that selectively deplete central 5HT or catechols, respectively $[40,41]$. The present data indicate that only depletion of central 5-HT by PCPA resulted in significant changes in Tyr-tub levels. PCPA could have an independent action upon the cytoskeleton. On the other hand these data may support a putative interaction between central 5-HT system and cytoskeleton dynamics while indicating absence of such interaction for what concerns the catecholaminergic system.

\section{Acute Treatment with Fluoxetine (SSRI)}

This was performed in order to influence the central serotonergic system and to verify putative subsequences on both 5-HT levels and Tyr-tub expression. This resulted in a significant increase of both 5-HT levels and Tyr-tub expression in whole brain up to approximately $217 \%$ and $203 \%$ of saline treated rats, respectively.

Up to date the 5-HT system is still one the major target of antidepressant SSRIs [17-21] thus the variation of 5-HT levels was to be expected.

Additionally, it is known that fluoxetine is a lipophilic chemical that can be located in subcellular fragments prepared from brain tissue of fluoxetine-treated rats [42]. Therefore, fluoxetine may enter the cell and interact with monoamine oxidase (MAO), enzyme present in both neurons and glia and that metabolises the classical monoamine neurotransmitters [43]. Consequently, the therapeutic actions of fluoxetine may [also] involve an inhibition of such enzyme and in particular the form MAO-B, which would result in a greater amount of 5-HT available for release as indeed already reported [44]. Furthermore, in vitro and in vivo study have shown that doses of $20 \mathrm{mg} / \mathrm{kg}$ produced a more-than$20 \%$ decrease in MAO A activity and a 10-15\% suppression of MAO B activity in the rat brain $[45,46]$.

Clinical studies have also shown that fluoxetine and other SSRI antidepressants, used at low dosage are beneficial in psychiatric disorders because they increase the availability or 
potency of neuroactive GABAergic steroids [for reviews see 47-49]. It appears that their ability to increase brain steroid biosynthesis is occurring at doses [i.e. $5 \mathrm{mg} / \mathrm{kg}$ in rats] devoid of significant action on brain 5-HT reuptake mechanisms $[50,51]$.
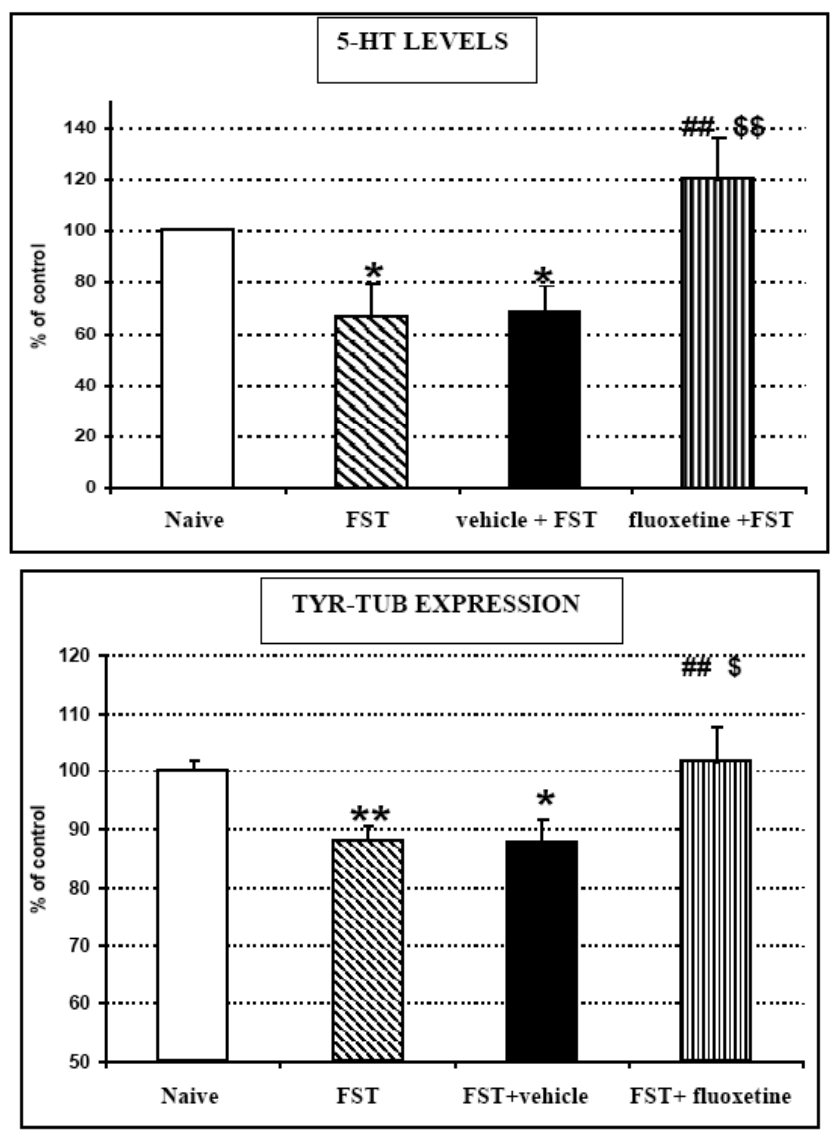

Fig. (4). TOP: 5-HT levels monitored by means of ex vivo DPV and BOTTOM: Tyr-Tub $(55 \mathrm{kDa})$ western blot immunoreactivity recorded in brain homogenates of naive (unstressed) rats or rats submitted to FST, FST + vehicle treatment or FST + fluoxetine treatment, respectively.

Results are expressed as percent of control (naive rats); $n=5$ each histogram,

mean \pm S.D.

Stats for 5-HT data:

ANOVA treatment effect: $\mathrm{F} 3,20=5.52504 \mathrm{p}=0.0078$

$* \mathrm{p}<0.05$ Unstressed versus FST or FST+ vehicle (Fisher's LSD Test)

$\# \# \mathrm{p}<0.01$ FST versus FST+fluoxetine (Fisher's LSD Test)

$\$ \$ p<0.05$ FST+ vehicle versus FST+fluoxetine (Fisher's LSD Test)

Stats for Tyr-Tub data:

ANOVA treatment effect $F 3,54=4.87733 \mathrm{p}=0.0047$

$* \mathrm{p}<0.05 * * \mathrm{p}<0.01$ Unstressed versus FST or FST+vehicle

(Fisher's LSD Test)

\#\#p<0.01 FST versus FST+fluoxetine (Fisher's LSD Test)

$\$ \mathrm{p}<0.05$ FST+vehicle versus FST+fluoxetine (Fisher's LSD Test)

${ }^{*} \mathrm{p}<0.05$ Unstressed vs FST or FST+saline (Fisher's LSD Test)

$\# \#$ p $<0.01$ FST vs FST+fluoxetine (Fisher's LSD Test)

$\$ \$ \mathrm{p}<0.05 \mathrm{FST}+$ saline vs FST+fluoxetine (Fisher's LSD Test)
Therefore they are proposed as new class of pharmacological tools for the management of anxiety, related mood disorders, dysphoria, and impulsive aggression so called "selective brain steroidogenic stimulants" (SBSSs). The molecular mechanisms subserving the fluoxetine induced facilitation on neurosteroidogenesis remain to be investigated and defined in terms of structural chemical related specificity in activating brain steroidogenesis, which is a novel and intriguing branch of psychopharmacology.

In our work, the dose of fluoxetine used is superior to the $5 \mathrm{mg} / \mathrm{kg}$ and already proven to act on the changing of monoamine concentrations at the synapses via the selective inhibition of 5-HT reuptake. Nevertheless, these two components of fluoxetine central mechanism of action have to be considered when regarding its influence on cytoskeletal dynamics. It is definitely known that some neurosteroids have a direct action on cytoskeletal protein such as as the microtubule associated protein 2 (MAP2) that has an important role in neuronal morphogenesis stimulating for instance the extension of neurites [52].

Indeed, results suggest that MAP2 expression may be necessary for both neurite extension and cessation of cell division as the specific suppression of MAP2 synthesis prevents the neuronal differentiation of embryonic carcinoma cells exposed to retinoic acid, as shown by the absence of neurites [53].

On the other hand, the proposed modification of Tyr-tub is an original observation. It could be due to an SSRI direct action on the cytoskeleton and/or it could be successive to changes on central serotonin activity, opening to the hypothesis of an interrelationship between these two systems.

\section{FST}

Such postulation was also challenged in animals submitted to FST following vehicle or fluoxetine treatment as described by Porsolt et al. [31]. FST is an animal model of depression widely used to predict the efficacy of antidepressant drugs [31]. Successively ex vivo analysis of brain 5-HT levels and Tyr-tub expression were performed. These two latter measurements were also carried out in control naive rats.

The pre-test session of the FST (15 min swimming, day 1) induces a state of behavioural despair that is thought to increase the duration of immobility during the $5 \mathrm{~min}$ swimming test session of day 2 (FST) [39]. Accordingly, here the rats submitted to FST did show a significant ( $\mathrm{p}<0.05$ Dunnett's test) increase of immobility up to approximately $158 \%$ of the values gathered in day 1 (pre-test day). In addition, during the FST, the fluoxetine treated rats displayed significantly lower immobility and higher swimming counts when compared to saline treated rats. Climbing counts were similar in both type of treatment (Table 1). In the successive parallel ex vivo electrochemical and western blot studies in whole brain it was observed that:

i) In saline treated rats 5-HT levels and Tyr-tub expression were both decreased to approximately $69 \%$ and $88 \%$ of corresponding levels monitored in naive control rats, respectively.

ii) In fluoxetine treated rats 5-HT levels and Tyr-tub expression were both increased up to approximately $120 \%$ and $104 \%$ of corresponding levels monitored in 
Table 2. Data Gathered in Three Groups of Rats:

1) Naïve control rats $(n=5)$ that were not submitted to FST neither injected.

2) Untreated rats $(n=5)$ that were submitted to FST.

3) Vehicle + FST rats $(\mathrm{n}=5)$ that were submitted to FST after sub-chronic treatment with saline $(600 \mathrm{ml}$ i.p.) as described in Methods.

\begin{tabular}{|c|c|c|c|}
\hline Tyr-tub & Naïve unstressed & FST & Vehicle +FST \\
\hline \hline mean & 100 & $88.2 *$ & $87.7 *$ \\
\hline sem & 1.8 & 2.5 & 4.2 \\
\hline 5-HT & Nä̈ve unstressed & FST & Vehicle +FST \\
\hline \hline mean & 100 & $66.7 *$ & $67.9 *$ \\
\hline sem & 4 & 12.9 & 10.7 \\
\hline
\end{tabular}

Data are expressed as mean \pm sem; *p<0.05: naïve unstressed versus FST or vehicle + FST ((Fisher's LSD Test).

naive control rats, respectively. On the other hand, when compared to data gathered from vehicle treated rats, these differences were approximately $150 \%$ and $120 \%$, respectively.

In addition, naive rats were submitted to FST in order to analyse the putative influence of systemic injection of vehicle $(\mathrm{NaCl} 0.9 \%, 600 \mu 1$ i.p.) upon the parameter measured. The data gathered within the naive rats were very similar to those observed in vehicle treated rats (see Table 2). Thus, injection of vehicle did not alter significantly the effect of FST upon 5-HT levels and Tyr-tub expression. Therefore, this data indicate that the reduction of 5HT levels and Tyrtub expression following FST is not altered significantly by the manipulation of the animal when submitted to i.p. treatment, thus supporting both these reductions as directly related to the FST and independent from the putative stressful manipulation of the animal due to the systemic injection.

These original parallel electrochemical and western blot results further support such combined methodology as useful concomitant analytical approach indicating that in rats submitted to FST a reduced neuronal plasticity can be detected together with coupled decreased activity of central serotonergic system. They are in agreement for instance and therefore corroborate with separate experiments showing i) the neuronal plasticity failure [13-15] and ii) the reduced central 5-HT levels in condition of depression [17].

All these data support a strict relationship between 5-HT and cytoskeleton as the two systems are modified in a parallel way in all the different types of treatments. Again, the pharmacological or behavioural induced changes of serotonergic levels were expected as already reported in the literature, while the original observation that FST modifies Tyrtub expression may lead to the hypothesis of a primary influence of the central 5-HT system upon the cytoskeleton condition. It has been shown that different acute stressful conditions [i.e. 5-min forced swim in cold water] result in hyperphosphorylation of microtubule-associated proteins such as TAU [54] and that neuronal TAU hyperphosphorylation decreases microtubule dynamics resulting in neuronal plasticity impairment [55].

On the other hand, fluoxetine was reported to have the ability to reverse stress-induced changes [56, 57] and that fluoxetine increases the phosphorylation of MAP-2 [58] that is amongst neuronal microtubule-associated proteins (MAPs) an abundant group of cytoskeletal components. This activity promotes microtubule dynamics [59] resulting in more TyrTub expression $[5,26]$. In the literature this type of studies is generally performed in the hippocampus, the evidence in our work that such effect of fluoxetine is detected in the whole brain may indicate a general activity over the CNS of such compound.

In conclusion, the present work supports the preliminary hypothesis about a direct serotonin and neuronal plasticity relationship [26] as it proposes that changes in central 5-HT levels obtained either within a behavioural test resulting in stress and/or depression states (FST) or via selective pharmacological treatments (i.e. PCPA, fluoxetine treatment) have direct influence upon the microtubular network resulting in modified activity of the neuronal plasticity.

In particular, the original hypothesis that the decreased 5HT levels observed in depression [17] may be selectively correlated to a reduced dynamic instability of the microtubular network could be formulated.

Finally, the direct relationship observed between 5-HT and the microtubular network can be proposed as a mechanism involved in the control of mood which may be an innovative target for alternative therapeutic approaches to treat depression.

\section{ACKNOWLEDGEMENTS}

For technical support to Dr. E. Vecchiato and Dr. C. Lazzarini.

\section{REFERENCES}

[1] Meninger V, Binet S. Characteristics of microtubules at the different stages of neuronal differentiation and maturation. Int Rev Cytol 1989; 114: 21-79.

[2] Luduena R. Multiple forms of tubulin: different gene products and covalent modifications. Int Rev Cytol 1998; 178: 207-75.

[3] Gundersen GG, Khawaja S, Bulinski JC. Postpolymerization detyrosination of $\alpha$-tubulin: a mechanism for subcellular differentiation of microtubules. J Cell Biol 1987; 105: 251-64.

[4] Contin MA, Sironi JJ, Barra HS, Arce CA. Association of tubulin carboxypeptidase with microtubules in living cells. Biochem J 1999; 339: 463-71.

[5] Contin MA, Arce CA. Tubulin carboxypeptidase/microtubules association can be detected in the distal region of neuronal processes. Neurochem Res 2000; 25(1): 27-36.

[6] Farina V, Tapparo A, Zedda M, Gadau S, Lepore G. Aluminum promotes neuronal plasticity events in a mouse neuroblastoma cell line. Neurosci Lett 2001; 312: 5-8 
[7] Cumming R, Burgoyne RD, Lytton NA. Immunocytochemical demonstration of $\alpha$-tubulin modification in the cerebellar cortex. $\mathrm{J}$ Cell Biol 1984; 98: 347-51.

[8] Farina V, Zedda M, Marongiu P, De Riu PL. Tubulin isoforms are differently expressed in developging and mature neurons: a study on cerebral cortex of newborn and adult rats. Eur J Histochem 1999; 43: 285-91.

[9] De Riu PL, Bianchi M, Zedda M, Marongiu P, Farina V. Brain plasticity in mirror focus: a study on tubulin expression. Proc. $5^{\text {th }}$ IDNA Conference. Cagliari, Italy, 1998.

[10] Friston KJ. The disconnection hypothesis. Schizophr Res 1998; 30: 115-25.

[11] Lauder JM. Ontogeny of the serotonergic system in the rat: serotonin as s developmental signal. Ann NY Acad Sci 1990; 600: 297 310

[12] Popoli M, Brunello N, Perez J, Racagni G. Second messengerregulated protein kinases in the brain: their functional role and the action of antidepressant drugs. J Neurochem 2000; 74: 21-33.

[13] Duman SR, Malberg J, Nagakawa S, D'Sa C. Neuronal plasticity and survival in mood disorder. Biol Psychcol 2000; 48: 732-9.

[14] Duman RS. Depression: a case of neuronal life and death? Biol Psychiatry 2004; 56(3): 140-5.

[15] Duman RS. Role of neurotrophic factors in the etiologyand treatment of mood disorders. Neuro Mol Med 2004; 5: 11-25.

[16] Dranovsky A, Hen R. Hippocampal Neurogenesis: Regulation by Stress and Antidepressants Biol Psychiatry 2006; 59(12): 1136-43.

[17] Blier P, de Montigny C. Current advances in trends in the treatment of depression. Trends Pharmacol Sci 1994; 15: 220-6.

[18] Den Boer JA, Bosker FJ, Slaap BR. Serotonergic drugs in the treatment of depressive and anxiety disorders. Human Psychopharmacology. Clin Exp 2000; 15: 315-36.

[19] Morishita S, Arita S. Differential effects of fluvoxamine, paroxetine and milnacipran for depression, especially with regard to age. Hum Psychopharmacol Clin Exp 2004; 19: 405-8.

[20] Berlanga C, Flores-Ramos M. Different gender response to serononergic and noradrenergic antidepressants: a comparative study of the efficacy of citalopram and reboxetine. J Affect Disord 2006; 95, 119-123.

[21] Morishita S, Kinoshita T. Predictors of response to sertraline in patients with major depression Hum Psychopharmacol Clin Exp 2008; 23: 647-51

[22] Nguyen PV, Woo NH. Regulation of hippocampal synaptic plasticity by cyclic AMP-dependent protein kinases. Prog Neurobiol 2003; 71: 401-37

[23] Feil R, Hofmann F, Kleppisch T. Function of cGMP-dependent protein kinases in the nervous system. Rev Neurosci 2005; 16: 2341.

[24] Pandey GN, Dwivedi Y. Focus on protein kinase A and protein Kinase C critical components of signal transduction system, in mood disorders and suicide. Int J Neuropsychopharmacol 2005; 8: $1-4$.

[25] Miyamoto S, Asakura M, Sasuga Y, et al. Effects of long-term treatment wiyh desipramine on microtubule proteins in rat cerebral cortex. Eur J Pharmacol 1997; 333; 279-87.

[26] Crespi F. Serotonin and neuronal plasticity relationship: a new mechanism involved in depression? Eur Neuropsychopharmacol 2002; 12: 191

[27] Pol O, Campmany L, Armario A. Inhibition of catecholamine synthesis with $\alpha$-methyl- $p$-tyrosine apparently increases brain serotonergic activity in the rat: no influence of previous chronic immobilization stress. Pharmacol Biochem Behav 1995; 52: 107-12.

[28] Moresco RM, Loc'h C, Ottaviani M, et al. Effects of dopamine on the in vivo binding of dopamine $\mathrm{D}_{2}$ receptor radioligands in rat striatum. Nucl Med Biol 1999; 26: 91-8.

[29] Dewar KM, Grondin L, Carli M, Lima L, Reader TA. [3H] paroxetine binding and serotonin content of rat cortical areas, hippocampus, neostriatum, ventral mesencephalic tegmentum, and midbrain raphe nuclei region following p-chlorophenylalanine and p-chloroamphetamine treatment. J Neurochem 1992; 58(1): 250-7.

[30] Koe BK, Weissmann A. Para-chlorophenylalanine: a specific depletor of brain serotonin. J Pharmacol Exp Ther 1966; 154: 499516.

[31] Porsolt R, Le Pichon M, Jalfre M. Depression: a new animal model sensitive to anti-depressant treatments. Nature 1977; 266: 730-2.

[32] Stamford J, Crespi F, Marsden CA. In vivo voltammetric methods for monitoring monoamine release and metabolism. In: Practical approach series monitoring neuronal activity. Oxford, UK: Irl Press 1992; pp.113-45

[33] Crespi F. In vivo voltammetry with micro-biosensors for analysis of neurotransmitter release and metabolism. J Neurosci Methods 1990; 34: 53-65.

[34] Crespi F, Martin KF, Marsden CA. Nafion coated carbon fibre electrodes combined with differential pulse voltammetry measure 5-HT release in vivo. Neuroscience 1988; 27: 885-96.

[35] Martin K, Marsden CA, Crespi F. In vivo electrochemistry with carbon fibre electrodes: principles and application to neuropharmacology.Trends Anal Chem 1988; 7: 334-9.

[36] Congestri F, Formenti F, Sonntag V, Crespi F. The selective D3 receptor antagonist SB-277011-A potentiates the effect of cocaine on extracellular dopamine in the nucleus accumbens: a dual coreshell voltammetry study in anesthetized rats. Sensors 2008; 8: 6936-51.

[37] Detke MJ, Rickels M, Lucki I. Active behaviors in the rat forced swimming test differentially produced by serotonergic and noradrenergic antidepressants. Psycopharmacology 1995; 121: 6672.

[38] Taltavull JF, Chefer VI, Shippenberg TS, Kiyatkin EA. Severe brain hypothermia as a factor underlying behavioural immobility during cold water forced swim. Brain Res 2003; 975: 244-7.

[39] Detke MJ, Lucki I. Detection of serotonergic and noradrenergic antidepressants in the rat forced swimming test: the effect of water depth. Brain Res 1996; 73: 43-6.

[40] DourishCT, Hutson PH, Curzon G. Para-chlorophenylalanine prevents feeding induced by the serotonin agonist 8-hydroxy-2-(di- $n$ propylamino) tetralin (8-OH-DPAT). Psychopharmacology 1986; 89: 467-71.

[41] Smith AD, Justice JB. The effect of inhibition of synthesis, release, metabolism and uptake on the microdialysis extraction fraction of dopamine. J Neurosci Methods 1994; 54: 75-82.

[42] Caccia S, Buczko W, DeGaetano G, Garattini S. Influence of dose and route of administration of fluoxetine and its metabolite norfluoxetine in the rat. Psychopharmacology 1990; 100: 509-14.

[43] Westlund KN, Denney RM, Kochersperger LM, Rose RM. Distinct monoamine oxidase-A and-B populations in primate brain. Science 1985; 230: 181-3.

[44] Leonardi ETK, Azmitia EC. MDMA (Ecstasy) Inhibition of MAO Type A and Type B: comparisons with fenfluramine and fluoxetine (prozac). Neuropsychopharmacology 1994; 10: 231-8

[45] Mukherjee J,Yang ZY. Evaluation of monoamine oxidase B inhibition by fluoxetine (Prozac): an in vitro and in vivo study. Eur $\mathrm{J}$ Pharmacol 1997; 337(1): 111-4.

[46] Mukherjee J,Yang ZY. Monoamine oxidase A inhibition by fluoxetine: an in vitro and in vivo study. Synapse 1999; 31(4): 2859.

[47] Dubrovsky BO. Steroids, neuroactive steroids and neurosteroids in psychopathology. Prog Neuropsychopharmacol Biol Psychiatry 2005; 29: 169-92.

[48] Barbaccia ML. Neurosteroidogenesis: relevance to neurosteroid actions in brain and modulation by psychotropic drugs. Crit Rev Neurobiol 2004; 16: 67-74.

[49] Van Broekhoven F, Verkes RJ. Neurosteroids in depression: a review. Psychopharmacology 2003; 165: 97-110.

[50] Pinna G, Costa E, Guidotti A. Fluoxetine and norfluoxetine stereospecifically and selectively increase brain neurosteroid content at doses that are inactive on 5-HT reuptake. Psychopharmacology 2006; 186: 362-72.

[51] Goren MZ, Kucukibrahimoglu E, Berkman K, Terzioglu B. Fluoxetine partly exerts its actions through GABA: a neurochemical evidence. Neurochem Res 2007; 32: 1559-65.

[52] Fontaine-Lenoir V, Chambraud B, Fellous A, et al. Microtubuleassociated protein 2 (MAP2) is a neurosteroid receptor. Proc Natl Acad Sci USA 2006; 13(12): 4711-6.

[53] Dinsmore JH, Solomon F. Inhibition of MAP2 expression affects both morphological and cell division phenotypes of neuronal differentiation. Cell 1991; 64: 817-26.

[54] Okawa Y, Ishiguro K, Fujita SC. Stress-induced hyperphosphorylation of TAU in the mouse brain. FEBS Lett 2003; 535(1-3): 183-9.

[55] Arendt T, Stieler J, Strijkstra AM, et al. Reversible paired helical filament-like phosphorylation of TAU is an adaptive process associated with neuronal plasticity in hibernating animals. J Neurosci 2003: 23: 6972-81 
[56] Grippo AJ, Beltz TG, Weiss RM, Johnson AK. The effects of chronic fluoxetine treatment on chronic mild stress-induced cardiovascular changes and anhedonia. Biol Psychiatry 2006; 59: 309-16.

[57] Surget A, Saxe M, Leman S, et al. Drug dependent requirement of hippocampal neurogenesis in a model of depression and of antidepressant reversal. Biol. Psychiatry 2008; 64: 293-301.

[58] Yanga C, Wanga G, Wanga H, Liua Z, Wanga X. Cytoskeletal alterations in rat hippocampus following chronic unpredictable mild stress and re-exposure to acute and chronic unpredictable mild stress. Behav Brain Res 2009; 205: 518-24.

[59] Hirokawa N. Microtubule organization and dynamics dependent on microtubule-associated proteins. Curr Opin Cell Biol 1994; 6: 74 81

(C) Francesco Crespi; Licensee Bentham Open.

This is an open access article licensed under the terms of the Creative Commons Attribution Non-Commercial License (http://creativecommons.org/licenses/by-nc/3.0/) which permits unrestricted, non-commercial use, distribution and reproduction in any medium, provided the work is properly cited. 